\title{
BMJ Open Referral pathways for patients with TIA avoiding hospital admission: a scoping review
}

Bridie Angela Evans, ${ }^{1}$ Khalid Ali, ${ }^{2}$ Jenna Bulger, ${ }^{1}$ Gary A Ford ${ }^{3}$ Matthew Jones, ${ }^{1}$ Chris Moore, ${ }^{4}$ Alison Porter, ${ }^{1}$ Alan David Pryce, ${ }^{5}$ Tom Quinn, ${ }^{6}$ Anne C Seagrove, ${ }^{1}$ Helen Snooks, ${ }^{1}$ Shirley Whitman, ${ }^{5}$ Nigel Rees, ${ }^{4}$ on behalf of the TIER Trial Research Management Group

To cite: Evans BA, Ali K Bulger J, et al. Referral pathways for patients with TIA avoiding hospital admission: a scoping review. BMJ Open 2017;7:e013443. doi:10.1136/bmjopen-2016013443

- Prepublication history for this paper is available online. To view these files please visit the journal online (http://dx.doi.org/10.1136/ bmjopen-2016-013443).

Received 12 July 2016 Revised 11 January 2017 Accepted 13 January 2017

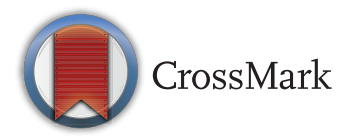

${ }^{1}$ Swansea University Medical School, Swansea, UK ${ }^{2}$ Brighton and Sussex Medical School, Brighton, UK ${ }^{3}$ Oxford University Hospitals NHS Foundation Trust, Oxford, UK

${ }^{4}$ Welsh Ambulance Service NHS Trust, Swansea, UK

${ }^{5}$ Lay Contributor c/o Swansea University Medical School, Swansea, UK

${ }^{6}$ Kingston University and St George's, University of London, London, UK

Correspondence to Dr Bridie Angela Evans; b.a.evans@swansea.ac.uk

\section{ABSTRACT}

Objective: To identify the features and effects of a pathway for emergency assessment and referral of patients with suspected transient ischaemic attack (TIA) in order to avoid admission to hospital.

Design: Scoping review.

Data sources: PubMed, CINAHL Web of Science, Scopus.

Study selection: Reports of primary research on referral of patients with suspected TIA directly to specialist outpatient services.

Data extraction: We screened studies for eligibility and extracted data from relevant studies. Data were analysed to describe setting, assessment and referral processes, treatment, implementation and outcomes.

Results: 8 international studies were identified, mostly cohort designs. 4 pathways were used by family doctors and 3 pathways by emergency department physicians. No pathways used by paramedics were found. Referrals were made to specialist clinic either directly or via a 24-hour helpline. Practitioners identified TIA symptoms and risk of further events using a checklist including the ABCD2 tool or clinical assessment. Antiplatelet medication was often given, usually aspirin unless contraindicated. Some patients underwent tests before referral and discharge. 5 studies reported reduced incident of stroke at 90 days, from $6-10 \%$ predicted rate to $1.3-2.1 \%$ actual rate. Between $44 \%$ and $83 \%$ of suspected TIA cases in these studies were referred through the pathways.

Conclusions: Research literature has focused on assessment and referral by family doctors and ED physicians to reduce hospitalisation of patients with TIA. No pathways for paramedical use were reported. We will use results of this scoping review to inform development of a paramedical referral pathway to be tested in a feasibility trial.

Trial registration number: ISRCTN85516498. Stage: pre-results.

\section{INTRODUCTION}

Transient ischaemic attack (TIA) is a neurological event characterised by the resolution

\section{Strengths and limitations of this study}

- This is the first attempt to systematically search and describe referral pathways for patients with transient ischaemic attack (TIA) to gain timely access to appropriate specialist assessment, thereby avoiding hospital admission.

- We followed a systematic approach based on guidance for carrying out a scoping review and reported our methods fully: that our research team included paramedics, ambulance service managers, nurses, stroke clinicians and patients alongside experienced trialists, provided a broad and complementary range of perspectives to implement our review and interpret findings.

- We balanced resources and timescales against need to inform intervention development in our feasibility study; we discussed methods and findings within the study team to assess and monitor processes.

- We did not assess the reporting quality of papers. However, all were published in international peer-reviewed journals and we have reported study results to aid interpretation, in line with recommendations.

- Our findings, which suggest there is potential for paramedics who are often the first healthcare professionals to attend, assess and refer suspected TIA cases, will be used to inform development of an intervention for paramedics to be tested in a feasibility trial.

of focal and non-focal symptoms within 24 hours and with limited associated sequelae. ${ }^{1}$ Clinical studies have demonstrated that patients who have a TIA are at risk of further TIAs, stroke and death. ${ }^{2-5}$ Delays in the processes of care for TIA have consequences for the health and satisfaction of patients. Inefficiencies in provision of care may increase the burden on health services, particularly emergency and secondary care. ${ }^{6}$ In the UK, stroke has a direct cost to the National Health Service (NHS) of £2.8 billion 
per year; informal care costs of £2.4 billion per year and costs the economy $£ 1.8$ billion per year. ${ }^{7}$

TIAs are not always regarded as emergencies since the stroke-like symptoms present and resolve in a short time without treatment. Symptoms may therefore be ignored or disregarded by patients, their families and even by first contact clinicians. ${ }^{5-10}$ Risk of stroke following a TIA can be assessed using the ABCD2 tool which considers age, blood pressure, clinical features of TIA, duration and presence of diabetes in a $0-7$ scoring system. ${ }^{11}$ Patients with low-risk TIA are diagnosed as having an ABCD2 score of $0-3$ which is associated with a $1 \%$ risk of stroke within the following 2 days. Higher ABCD2 scores (4-5 or 6-7) are associated with greater risk of stroke during the following 2, 7, 30 and 90 days after a TIA. ${ }^{11}$ In the UK, the National Institute for Health and Care Excellence (NICE) recommends that low-risk patients with TIA are assessed by a specialist within 1 week, and that high-risk patients with TIA are assessed by a specialist within 24 hours. ${ }^{12}$ Many patients present with suspected TIA to the emergency ambulance service and then encounter delays in hospital before being seen by a stroke or TIA specialist. ${ }^{13}$

Treatment of TIA has been identified as one of the conditions potentially able to receive an alternative response to traditional conveyance by ambulance to hospital. ${ }^{14}$ Low-risk patients with TIA can be managed safely and effectively as outpatients, without hospital-based treatment. ${ }^{15}{ }^{16}$ However, risk of hospitalisation for a patient with TIA increases with emergency department (ED) overcrowding, suggesting clinicians' decisionmaking is affected by the pressured environment. ${ }^{17}$ As the role of ambulance services in the UK and internationally has shifted, from predominantly assessment and transport to hospital to clinical assessment and decision-making on scene, ambulance services are exploring alternative care pathways for appropriate low-risk patients, to refer direct to relevant specialist services (eg, mental health services, diabetes specialist) or leave patients at home. ${ }^{18-27}$ Increased demand for emergency and prehospital care has been highlighted by the media on numerous occasions. ${ }^{28-30}$ Paramedics routinely identify and assess patients who suffered stroke before transporting direct to stroke centres. ${ }^{14}$ Some ambulance services are now setting up alternative pathways for presumed low-risk suspected TIA with protocols for direct referral to specialist services, avoiding the ED. Recent guidelines recommend paramedics use a validated tool to identify patients' risk of further TIA or stroke and safely refer to specialist TIA services. ${ }^{14}{ }^{31}$ However, the ABCD2 tool has not yet been validated in a prehospital context and the evidence is inconclusive about how best to assess risk in this patient group and safely make referrals along appropriate clinical pathways, ${ }^{31-34}$ new knowledge about safety, effectiveness and costs of this new model of care is therefore limited. ${ }^{14} 35$

The Welsh Ambulance Service NHS Trust and PRIME Centre Wales received funding to assess the feasibility of assessment and referral of patients with low-risk TIA by paramedics directly to TIA clinic rather than conveyance to the ED. The TIER (Transient Ischaemic Attack 999 Emergency Referral) study is designed to test whether this intervention is acceptable and whether study design, recruitment and data collection are achievable in order to plan a fully powered randomised trial if preset progression criteria are met. ${ }^{36}$ Our protocol is available from the authors. We have obtained ethical approval and begun recruitment. Potential benefits of the new pathway include timely specialist review for patients with low acuity TIA without: adverse consequences; the inconvenience of ED attendance; and unnecessary cost to the NHS.

To inform development of an ambulance paramedic referral for TIA, we conducted a scoping review of the literature to identify existing prehospital emergency pathways and evidence about their implementation and effectiveness. Scoping reviews are suitable for undertaking rapid mapping of the literature in areas where little previous investigation has been undertaken ${ }^{37} 38$ and can inform further research and practice. ${ }^{37-45}$ They are concerned with 'contextualizing knowledge... and then setting this within policy and practice contexts' (p. 10). ${ }^{39}$

The objective of this review is to identify the features and effects of a pathway for emergency assessment and referral of patients with suspected TIA in order to avoid admission to hospital and gain timely access to appropriate outpatient-based specialist assessment.

\section{METHODS}

We followed guidance for undertaking a rapid scoping review, ${ }^{38} 46$ while noting that specific advice for scoping reviews is not available ${ }^{45}$ (see also http://www. equator-network.org/).

\section{Eligibility criteria}

We included studies reporting descriptive and effectiveness data about assessment and referral pathways for patients with TIA directly referred to specialist services, avoiding hospital admission. We excluded studies where patients were admitted to a designated observation unit or stroke centre or who were treated in the ED without receiving an outpatient referral because these treatment routes did not incorporate referral to avoid admission to a secondary care centre. We also excluded studies which did not report enough information to allow us to replicate the pathway. In line with advice to search widely across the literature, ${ }^{37} 41$ we sought any study method. Our inclusion and exclusion criteria are shown in table 1.

\section{Information sources and search strategy}

We searched four electronic databases (PubMed, CINAHL, Web of Science and Scopus). We tested and revised our search strategy to focus on TIAs and the 
Table 1 Inclusion and exclusion criteria for studies included in the scoping review

\begin{tabular}{|c|c|c|}
\hline & Inclusion criteria & Exclusion criteria \\
\hline Population & Patients presenting with suspected TIA & $\begin{array}{l}\text { Patients presenting with ongoing symptoms } \\
\text { suggestive of stroke } \\
\text { Patients presenting with recurrent or crescendo } \\
\text { focal neurological symptoms }\end{array}$ \\
\hline Intervention & $\begin{array}{l}\text { Assessment, referral and treatment for suspected TIA in } \\
\text { order to avoid admission to hospital } \\
\text { Intervention described in enough detail to be replicable } \\
\text { Attendance at ED as part of a referral pathway to avoid } \\
\text { hospital admission }\end{array}$ & $\begin{array}{l}\text { Admission to hospital } \\
\text { Admission to a designated observation ward or } \\
\text { unit } \\
\text { ED treatment without a referral pathway } \\
\text { Lack of information about assessment, treatment } \\
\text { or referral criteria and processes }\end{array}$ \\
\hline $\begin{array}{l}\text { Comparator } \\
\text { Outcomes }\end{array}$ & $\begin{array}{l}\text { Any study design: no comparator necessary } \\
\text { Outcomes not necessary }\end{array}$ & \\
\hline Study design & $\begin{array}{l}\text { Any study design } \\
\text { English language } \\
\text { Published 2005-2015 }\end{array}$ & Editorial, opinion and discussion pieces \\
\hline
\end{tabular}

prehospital setting after initial searches, which included the terms 'mini-stroke', 'stroke', 'pathway', 'care' and 'treatment' identified the literature on stroke treatment, care pathways and guidelines rather than TIAs. ${ }^{38}$ Our research team discussed results of early scoping searches allowing us to clarify the features of a referral pathway (eg, from any community or prehospital route) and patient group (eg, patients no longer displaying TIA symptoms). ${ }^{44}$ In this way, we combined a broad question with a clearly articulated scope of enquiry. ${ }^{40}$ Our final search strategy included the following search terms:

(TIA OR Transient Ischaemic Attack OR Transient ischemic attack) AND (999 OR prehospital OR prehospital OR ambulance OR ambulances OR ambulance* $^{*}$ OR paramedic* OR emergency).

We used MeSH headings and key words where possible. We carried out our searches in January and February, 2016. We limited searches to English language reports published between 2005 and 2015 .

\section{Study selection}

Two authors (BAE and MJ) undertook a two-stage screening process against inclusion criteria for selection of studies identified through electronic searches: (1) screening by title and abstract to identify potentially eligible studies; and (2) assessing full papers to confirm those suitable for inclusion in this review. Differences were resolved in discussion, with a third reviewer (ACS) available to mediate if required.

\section{Data extraction, presentation and reporting}

We extracted data on a predefined table. We adapted this from the Cochrane Collaboration Handbook ${ }^{48}$ to ensure our review approach retained systematic and clear standards of reporting. We presented results according to PRISMA guidance ${ }^{49}$ using a flow chart, table and narrative summaries to chart key items of information. ${ }^{50}$ Data extraction was undertaken by BAE and JB.

\section{Quality assessment}

We did not assess the quality of evidence reported by papers included in our scoping review. Arksey and O'Malley $^{38}$ state that scoping reviews should not present the 'weight' (p. 18) of evidence, which they define as robustness or generalisability, by assessing the quality of reporting by included papers. However, we sought to clearly report study findings so that the reader can determine potential bias in this paper's findings and discussion. $^{38}$

\section{RESULTS}

\section{Characteristics}

Of the 2374 references reviewed, 31 full papers were obtained and 9 papers reporting 8 studies met our inclusion criteria (see figure 1). Characteristics of included studies are reported in table 2. Two papers each reported studies undertaken in the $\mathrm{UK}^{6}{ }^{6}{ }^{5}$ France $^{5253}$ and Australia ${ }^{5455}$ and one in Canada. ${ }^{56}$ Two papers reported the protocol ${ }^{57}$ and results ${ }^{58}$ of a study undertaken in New Zealand. One randomised controlled trial was identified $;{ }^{58}$ other studies incorporated a control group, either using a before and after ${ }^{65153}$ or cohort design. ${ }^{53} 57$ Two papers ${ }^{56} 57$ presented a study with no results included. Number of patients ranged from 185 to 1085 . Data collection periods ranged from 3 to 36 months. All papers were published in international peer-reviewed journals reporting general medical, stroke or neurological studies.

\section{Referral and treatment pathway}

Three studies described a referral pathway initiated in the ED by physicians when presented with a patient with suspected TIA. ${ }^{53-55}$ Patients were assessed against 
Figure 1 Search results.

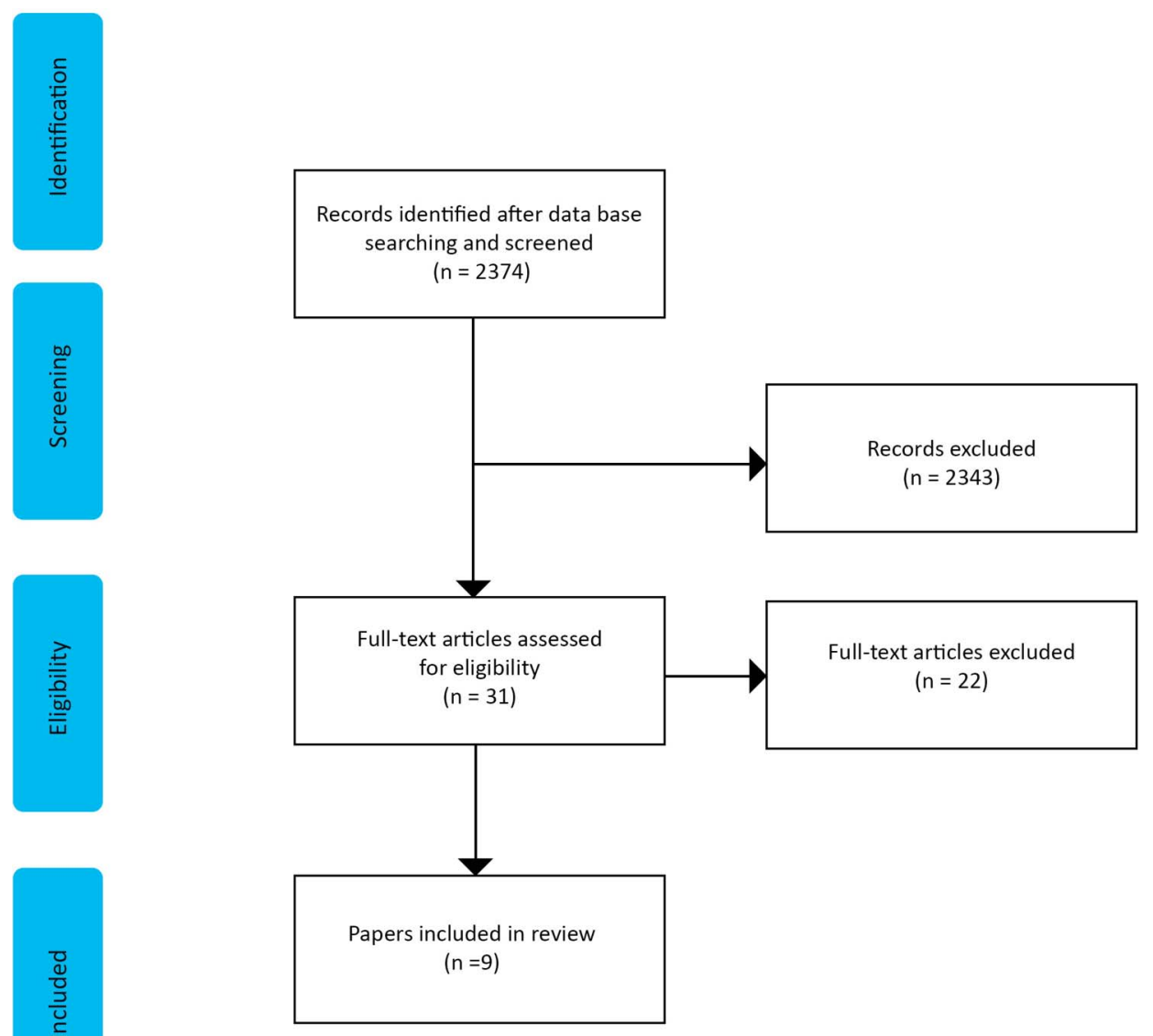

predefined criteria, ${ }^{54}$ a checklist ${ }^{55}$ or algorithm ${ }^{52}$ and then referred to a specialist clinic instead of being admitted for evaluation at the ED. Appointment arrangements varied between referral models. In the Monash TIA Triaging Treatment (M3T) pathway, ${ }^{54}$ a stroke registrar and nurse triaged new referrals and made appointments according to priority. Appointments reflected clinical need in the Griffiths et $a l^{55}$ study also and could be provided the same day if clinically required $^{5455}$ or within $4-6$ weeks if antiplatelet treatment had been initiated. ${ }^{54}$ However, Montassier et $a \tilde{\rho}^{3}$ reported that appointments were made for 8-15 days after referral. In the Griffiths et a $\tilde{l}^{55}$ study, patients received an education pack with instructions to follow-up with the general practitioner and call an ambulance if symptoms recurred.

The five other studies described a referral pathway which was initiated by the family doctor when a patient presented to them. In three studies, the doctor used a checklist (ABCD2 or one provided for the study) to identify patients with suspected low-risk TIA. The doctor then called a consultant-led 24-hour telephone hotline ${ }^{51} 5256$ to gain specialist advice and referral to stroke treatment service according to symptom severity and urgency. The doctor was able to discuss symptoms and severity with the specialist staff and agree whether referral was required and how soon the patient should be seen if an appointment was agreed to be necessary. ${ }^{51}{ }^{56}$ In the fourth study, ${ }^{6}$ the doctor directly referred patients with suspected TIA to a daily specialist clinic where no appointment was required. The clinic then confirmed the doctor's diagnosis and arranged for treatment to begin. Rothwell et $a l^{6}$ and Lavallée et $a \tilde{l}^{2}$ reported that clinic treatment reports and advice were sent to the patient's family doctor detailing blood tests, brain scans and prescribed medication for hypertension and anticoagulation to reduce risk of further TIAs. Family practitioners were advised of the new referral services through letters and leaflets which included information about risks, diagnosis and management of stroke and TIAs. Ranta et $a \vec{P}^{7}$ described an online decision support tool accessed by family doctors through a menu button situated on the navigation bar of their practice management software. This provided a single page of tick boxes concerning relevant aspects of presenting illness history and a brief focused physical examination. The software automatically populated fields for relevant medical history (such as diabetes and smoking) from the practice management system. Using inputted data, the software confirmed or rejected TIA or stroke as the likely diagnosis. If confirmed, it generated a triage option based on the ABCD2 score supplemented by variables from the New Zealand TIA guidelines. For low-risk patients, general practitioners (GPs) were given two 
Table 2 Characteristics of included studies

\begin{tabular}{|c|c|c|c|c|}
\hline Reference & Country & Method & Sample size & $\begin{array}{l}\text { Period of data } \\
\text { collection }\end{array}$ \\
\hline $\begin{array}{l}\text { Sanders } \\
\text { et } a \Gamma^{5^{4}}\end{array}$ & Victoria, Australia & $\begin{array}{l}\text { Prospective before and after } \\
\text { study }\end{array}$ & $\begin{array}{l}\text { Before intervention: } 169 \\
\text { patients } \\
\text { After intervention: } 301 \\
\text { confirmed TIA cases }\end{array}$ & $\begin{array}{l}\text { Before: } 12 \text { months } \\
\text { (2003-2004) } \\
\text { After: } 36 \text { months } \\
\text { (2004-2007) }\end{array}$ \\
\hline $\begin{array}{l}\text { Montassier } \\
\text { et } a^{53}\end{array}$ & Nantes, France & Prospective cohort study & 118 patients & $\begin{array}{l}12 \text { months } \\
\text { January to } \\
\text { December } 2009\end{array}$ \\
\hline $\begin{array}{l}\text { Griffiths } \\
\text { et } a)^{55}\end{array}$ & $\begin{array}{l}\text { New South Wales, } \\
\text { Australia }\end{array}$ & Prospective cohort study & 200 patients & $\begin{array}{l}22 \text { months } \\
\text { October } 2008 \text { to July } \\
2010\end{array}$ \\
\hline $\begin{array}{l}\text { Lavallee } \\
\text { et } a \digamma^{2}\end{array}$ & Paris, France & Prospective cohort study & 1085 patients & $\begin{array}{l}24 \text { months } \\
\text { January } 2003 \text { to } \\
\text { December } 2005\end{array}$ \\
\hline $\begin{array}{l}\text { Rothwell } \\
\text { et af }\end{array}$ & $\begin{array}{l}\text { Oxfordshire, } \\
\text { England }\end{array}$ & $\begin{array}{l}\text { Prospective before and after } \\
\text { study nested within a } \\
\text { population-based incidence } \\
\text { study of all TIA and stroke } \\
\text { (OXVASC study) }\end{array}$ & $\begin{array}{l}644 \text { patients presented with } \\
\text { TIA or stroke } \\
281 \text { referred for outpatient } \\
\text { assessment using EXPRESS } \\
\text { treatment protocol }\end{array}$ & $\begin{array}{l}30 \text { months } \\
1 \text { October } 2004 \text { to } \\
31 \text { March } 2007\end{array}$ \\
\hline Kerr et $a^{\Gamma^{1}}$ & Lothian, Scotland & $\begin{array}{l}\text { Audit of telephone hotline and } \\
\text { referral within prospective before } \\
\text { and after study of reconfigured } \\
\text { stroke service }\end{array}$ & 376 calls to hotline & 3 months \\
\hline $\begin{array}{l}\text { Jeerakathil } \\
\text { et } a{ }^{56}\end{array}$ & Alberta, Canada & $\begin{array}{l}\text { Algorithm and hotline pathway } \\
\text { developed through consensus } \\
\text { process. Reported in protocol } \\
\text { for before and after study }\end{array}$ & Study protocol & $\begin{array}{l}\text { 15-month } \\
\text { implementation } \\
\text { period }\end{array}$ \\
\hline $\begin{array}{l}\text { Ranta et } a \rho^{77} \\
\text { Ranta et } a{ }^{58}\end{array}$ & New Zealand & $\begin{array}{l}\text { Cluster randomised controlled } \\
\text { trial }\end{array}$ & $\begin{array}{l}\text { Study protocol } \\
\text { Results }^{58} \\
56 \text { general practices ( } 29 \\
\text { intervention) } \\
172 \text { intervention group patients } \\
119 \text { intervention group patients }\end{array}$ & $\begin{array}{l}13.5 \text { months } \\
24 \text { February } 2012 \text { to } \\
15 \text { May } 2013\end{array}$ \\
\hline
\end{tabular}

options. The first was to refer to outpatient TIA clinic using an automatically generated referral form. This contained all the information needed by a specialist to prioritise patients appropriately. Or the doctor could chose to manage the patient in the community following a step-by-step process covering prescriptions, radiology referral and information forms to give to the patient.

Studies reported a wide range of criteria to include and exclude patients (see table 3). Jeerakathil et $a l^{56}$ and Griffiths et $a \bar{l}^{55}$ used the ABCD2 scores to identify patients with suspected low-risk TIA. The decision support system described by Ranta et a $\bar{l}^{57}$ used ABCD2 scores supplemented by other variables taken from the New Zealand TIA guidelines. Kerr et $a \varphi^{1}$ and Montassier et $a l^{53}$ reported that doctors used an algorithm which considered time since symptom onset, symptoms experienced, extent of recovery and presence of atrial fibrillation. ED physicians in the Sanders et $a l^{54}$ study applied the International Classification of Diseases (ICD) 10 Australian Modification TIA code G45.8 or G45.9 while family doctors in the Lavallee et $a \bar{l}^{52}$ study made their assessments based on clinical expertise. Rothwell et at did not specify how family doctors assessed TIA.

Common features of pathways included the following:

- Suspected TIA diagnosis and risk assessment were made using a symptom-based algorithm or the ABCD2 score;

- Low-risk patients with suspected TIA, suitable for the referral pathway, had an ABCD2 score <4 (where stated);

- Patients could be referred to clinic without appointment, via a central contact point or electronic system which led to arrangements for attendance during the next 2 weeks;

- Antiplatelet therapy, generally aspirin unless contraindicated, was prescribed before discharge;

- Patients received comprehensive tests and further treatment at outpatient clinic (such as blood tests, brain scans, medication for hypertension and anticoagulation).

Further details about the referral and treatment pathways are provided in table 3 . 


\begin{tabular}{|c|c|c|c|c|c|}
\hline Study & $\begin{array}{l}\text { Setting and } \\
\text { intervention }\end{array}$ & $\begin{array}{l}\text { Assessment and } \\
\text { recognition of TIA }\end{array}$ & $\begin{array}{l}\text { Criteria for referral pathway } \\
\text { (inclusion/exclusion } \\
\text { criteria) }\end{array}$ & Referral process & Management or treatment \\
\hline $\begin{array}{l}\text { Sanders } \\
\text { et } a \Gamma^{F^{4}}\end{array}$ & $\begin{array}{l}\text { ED } \\
\text { Triage based on clinical } \\
\text { expertise in consultation } \\
\text { with stroke team; referral } \\
\text { to stroke clinic (priority or } \\
4-6 \text { weeks) }\end{array}$ & $\begin{array}{l}\text { ED physician assesses } \\
\text { patient for TIA. Diagnosis } \\
\text { confirmed by stroke } \\
\text { neurologist after clinical } \\
\text { consultation. } \\
\text { All patients were assigned } \\
\text { ICD10 Australian } \\
\text { Modification TIA code } \\
\text { G45.8 or G45.9. }\end{array}$ & $\begin{array}{l}\text { Definition of TIA for diagnosis } \\
\text { into M3T pathway: 'acute loss } \\
\text { of focal cerebral or monocular } \\
\text { function with symptoms } \\
\text { lasting <24 hours and thought } \\
\text { to be due to inadequate } \\
\text { cerebral or ocular blood } \\
\text { supply as a result of arterial } \\
\text { thrombosis or embolism'. }\end{array}$ & $\begin{array}{l}\text { ED physician faxes } \\
\text { standardised TIA referral to } \\
\text { daily TIA clinic to facilitate } \\
\text { outpatient review. Stroke } \\
\text { registrar and nurse triage } \\
\text { referrals daily with priority } \\
\text { appointments for ipsilateral } \\
\text { internal carotid artery } \\
\text { stenosis } \geq 50 \% \text {; confirmed } \\
\text { symptomatic stenosis } \geq 70 \% \text {; } \\
\text { AF. Other patients seen } \\
\text { within 4-6 weeks if } \\
\text { antiplatelet therapy is started } \\
\text { in ED. }\end{array}$ & $\begin{array}{l}\text { M3T treatment pathway: } \\
\text { 1. Emergency physician evaluation } \\
\text { of patient in consultation with } \\
\text { stroke team } \\
\text { 2. Urgent CT brain imaging, ECG } \\
\text { and baseline blood tests (forms } \\
\text { marked TIA pathway to } \\
\text { expedite) } \\
\text { 3. Antiplatelet therapy/warfarin/ } \\
\text { antihypertensive therapies/ } \\
\text { lipid-lowering therapies } \\
\text { (depending on test results) }\end{array}$ \\
\hline $\begin{array}{l}\text { Montassier } \\
\text { et } a^{F^{3}}\end{array}$ & $\begin{array}{l}\text { ED } \\
\text { Triage based on decision } \\
\text { algorithm; referral to } \\
\text { stroke clinic (8-15 days) }\end{array}$ & $\begin{array}{l}\text { ED physician uses } \\
\text { decision algorithm: yes/no } \\
\text { answers } \\
\text { Total recovery of } \\
\text { symptoms } \\
\text { Normal physical } \\
\text { examination Normal blood } \\
\text { tests results (white cell } \\
\text { counts and platelet counts, } \\
\text { red blood cells, glucose, } \\
\text { ionogram and creatinine) } \\
\text { ECG negative for AF } \\
\text { Cranial CT negative for } \\
\text { bleeding or other diagnosis }\end{array}$ & $\begin{array}{l}\text { All yes=discharge to } \\
\text { outpatient TIA evaluation } \\
\text { One no=admit patient }\end{array}$ & $\begin{array}{l}\text { All discharged patients were } \\
\text { managed as outpatients in } \\
8-15 \text { days } \\
\text { Antiplatelet therapy started } \\
\text { before discharge. }\end{array}$ & $\begin{array}{l}\text { At outpatient clinic ( } 8-15 \text { days later), } \\
\text { all received extracranial Doppler } \\
\text { testing of supra aortic arteries and } \\
\text { vascular neurology consultation }\end{array}$ \\
\hline $\begin{array}{l}\text { Griffiths } \\
\text { et } a p^{55}\end{array}$ & $\begin{array}{l}\text { ED } \\
\text { Triage based on ABCD2 } \\
\text { checklist; referral for } \\
\text { neurological review and } \\
\text { stroke clinic (timings } \\
\text { based on risk } \\
\text { stratification) }\end{array}$ & $\begin{array}{l}\text { ED physician uses ABCD2 } \\
\text { checklist to identify TIA } \\
\text { and risk status }\end{array}$ & $\begin{array}{l}\text { Exclusion: } \\
\text { ABCD2 scores } \geq 4 \text { or high-risk } \\
\text { features (neurologist } \\
\text { contacted) } \\
\text { Inclusion: } \\
\text { score }<4 \text { and no high-risk } \\
\text { features (including known } \\
\text { carotid disease, AF, } \\
\text { crescendo TIA) }\end{array}$ & $\begin{array}{l}\text { Fax request by departmental } \\
\text { secretary for expedited } \\
\text { neurologist review. } \\
\text { Refer patients to outpatient } \\
\text { CT angiography or carotid } \\
\text { ultrasound and request } \\
\text { echocardiogram and Holter } \\
\text { monitor scan to exclude } \\
\text { patients with haemorrhage } \\
\text { Initiate antiplatelet therapy if } \\
\text { not already on warfarin }\end{array}$ & $\begin{array}{l}\text { After neurologist review, patients } \\
\text { with ABCD2 scores } \geq 4 \text { could be } \\
\text { discharged. Patients provided with } \\
\text { patient education pack with } \\
\text { instructions: } \\
\text { How to start aspirin and aspirin/ } \\
\text { dipyridamole } \\
\text { Follow-up with GP within } 7 \text { days } \\
\text { Call ambulance if symptoms recur. } \\
\text { Departmental secretary contacts } \\
\text { patient and arranges follow-up with } \\
\text { neurologist. }\end{array}$ \\
\hline
\end{tabular}




\begin{tabular}{ll}
\hline Study & $\begin{array}{l}\text { Setting and } \\
\text { intervention }\end{array}$ \\
\hline Lavallée & $\begin{array}{l}\text { Primary care } \\
\text { et a } \text { F }^{2}\end{array}$ \\
& $\begin{array}{l}\text { Triage based on clinical } \\
\text { expertise with access to } \\
\text { 24-hour consultant-led } \\
\text { hotline and outpatient } \\
\text { stroke clinic }\end{array}$
\end{tabular}

stroke clinic

Assessment and
recognition of TIA
Family doctor identifies
TIA

\section{Criteria for referral pathway}

(inclusion/exclusion criteria)

Focal symptoms of brain or retinal dysfunction

Sudden onset and presumed to be related to ischaemia Patients had subsequently made total recovery

GP identifies suspected

No details provided

TIA. No details provided of assessment or recognition process.

\section{Referral process}

Family doctor calls 24-hour hotline if suspects TIA

Family doctor phone call triaged as TIA by stroke nurse (0900-1700) or senior vascular neurologist (17000900)=patient attends clinic

GP directly refers patients with suspected TIA to daily afternoon TIA/minor stroke clinic (no appointment necessary)

\section{Management or treatment}

1. Assessment within 4 hours of admissionClinical assessment by vascular neurologist

2. Tests: MRI or CT brain imaging; ultrasonography and transcranial Doppler imaging;

electrocardiography; blood tests for lipid profile, iconography, red and white cell count and platelet count, glucose, haemoglobin A,

$C$ reactive protein, creatinine

3. Vascular neurologist discusses case with referral doctor. Patient identified for discharge (unless admission criteria met)

4. Prevention therapy targets sent to family doctor (blood pressure, LDL cholesterol, aspirin administration, smoking status and treatment started if possible)

5. Antithrombotic treatment started

6. Patients given anticoagulant, antiplatelet or carotid revascularisation as appropriate

7. Discharge

Stroke clinic confirms diagnosis and begin treatment:

Aspirin or clopidogrel

Simvastatin

Blood pressure lowering

Anticoagulation

4-week prescription provided for all medication

CT brain scan obtained for patients with incomplete resolution of

symptoms at time of assessment Report of assessment,

investigations and treatment faxed to GP within 24 hours 


\begin{tabular}{|c|c|c|c|c|c|}
\hline Study & $\begin{array}{l}\text { Setting and } \\
\text { intervention }\end{array}$ & $\begin{array}{l}\text { Assessment and } \\
\text { recognition of TIA }\end{array}$ & $\begin{array}{l}\text { Criteria for referral pathway } \\
\text { (inclusion/exclusion } \\
\text { criteria) }\end{array}$ & Referral process & Management or treatment \\
\hline Kerr et $a^{51}$ & $\begin{array}{l}\text { Primary care } \\
\text { Triaging algorithm with } \\
\text { access to 24-hour } \\
\text { consultant-led hotline } \\
\text { and outpatient stroke } \\
\text { clinic (additional } \\
\text { appointment slots } \\
\text { created for pathway) }\end{array}$ & $\begin{array}{l}\text { Algorithm provided to GPs: } \\
\text { 1. Does patient have focal } \\
\text { neurological deficits? } \\
\text { 2. Are symptoms still } \\
\text { present? } \\
\text { 3. Did symptoms come on } \\
\text { rapidly? } \\
\text { 4. Did symptoms start } \\
\text { within past } 4 \text { hours? } \\
\text { 5. Did symptoms start } \\
\text { while patient was } \\
\text { awake? }\end{array}$ & $\begin{array}{l}\text { Answers to five algorithm } \\
\text { questions:All yes, ring } 999 \text { : } \\
\text { may need thrombolysis } \\
\text { q2 yes, q4 or q5 no: discuss } \\
\text { with stroke consultant today: } \\
\text { ring bed bureau or hotline } \\
\text { q2 no: ring stroke line, patient } \\
\text { seen within } 7 \text { days } \\
\text { q1 no: unlikely TIA, refer to } \\
\text { another service }\end{array}$ & $\begin{array}{l}\text { Options for GP/consultant in } \\
\text { discussion via telephone } \\
\text { helpline: } \\
\text { Appointment time for GP to } \\
\text { immediately give patient } \\
\text { Go to ED } \\
\text { Call } 999 \\
\text { Refer patient to appropriate } \\
\text { service } \\
\text { Advice but agree no further } \\
\text { secondary assessment } \\
\text { needed }\end{array}$ & No details provided \\
\hline $\begin{array}{l}\text { Jeerakathil } \\
\text { et } a^{56}\end{array}$ & $\begin{array}{l}\text { Primary care } \\
\text { Triaging algorithm with } \\
\text { access to 24-hour } \\
\text { consultant-led hotline } \\
\text { and outpatient stroke } \\
\text { clinic }\end{array}$ & $\begin{array}{l}\text { Triaging algorithm for } \\
\text { primary care physicians } \\
\text { when viewing patients with } \\
\text { suspected TIA or stroke to } \\
\text { assess risk-high, medium } \\
\text { or low }\end{array}$ & $\begin{array}{l}\text { High-risk: (1) symptom onset } \\
\text { within past } 48 \text { hours with any } \\
\text { of the following-motor deficit } \\
\text { lasting more than } 5 \text { min; } \\
\text { speech deficit lasting more } \\
\text { than } 5 \text { min; ABCD } 2 \text { score } \geq 4 \text {; } \\
\text { (2) atrial fibrillation with TIA. } \\
\text { Medium risk: (1) symptom } \\
\text { onset between } 48 \text { hours and } \\
7 \text { days with any of the } \\
\text { following-motor deficit } \\
\text { lasting more than } 5 \text { min; } \\
\text { speech deficit lasting more } \\
\text { than } 5 \text { min; ABCD } 2 \text { score } \geq 4 \text {. } \\
\text { Low-risk: (1) symptom onset } \\
\geq 7 \text { days; (2) symptom onset } \\
\leq 7 \text { days without the presence } \\
\text { of high-risk symptoms. } \\
\text { Unsure: physician contact } 24 \\
\text { stroke hotline for immediate } \\
\text { access to stroke specialist }\end{array}$ & $\begin{array}{l}\text { High-risk: physician contacts } \\
24 \text { hour hotline for immediate } \\
\text { access to stroke expert. } \\
\text { Patient assessed by stroke } \\
\text { specialist and has } \\
\text { investigations completed } \\
\text { within } 24 \text { hours. } \\
\text { Medium risk: patients are } \\
\text { seen promptly in nearest } \\
\text { stroke prevention clinic } \\
\text { (within } 3 \text { days) } \\
\text { Low-risk: patients seen soon } \\
\text { in nearest stroke prevention } \\
\text { clinic (within } 2 \text { weeks) } \\
\text { Unsure: based on advice of } \\
\text { stroke specialist }\end{array}$ & No details provided \\
\hline $\begin{array}{l}\text { Ranta } \\
\text { et } a^{p^{7}}\end{array}$ & $\begin{array}{l}\text { Primary care } \\
\text { Internet-based clinical } \\
\text { decision support tool }\end{array}$ & $\begin{array}{l}\text { GP uses decision support } \\
\text { tool; single page of tick } \\
\text { boxes covering }\end{array}$ & $\begin{array}{l}\text { Software confirms or rejects } \\
\text { TIA/stroke diagnosis based } \\
\text { on data entered by GP. }\end{array}$ & $\begin{array}{l}\text { Software offers GP two } \\
\text { options: }\end{array}$ & $\begin{array}{l}\text { 1. Software generates referral form } \\
\text { for TIA outpatient clinic with }\end{array}$ \\
\hline
\end{tabular}




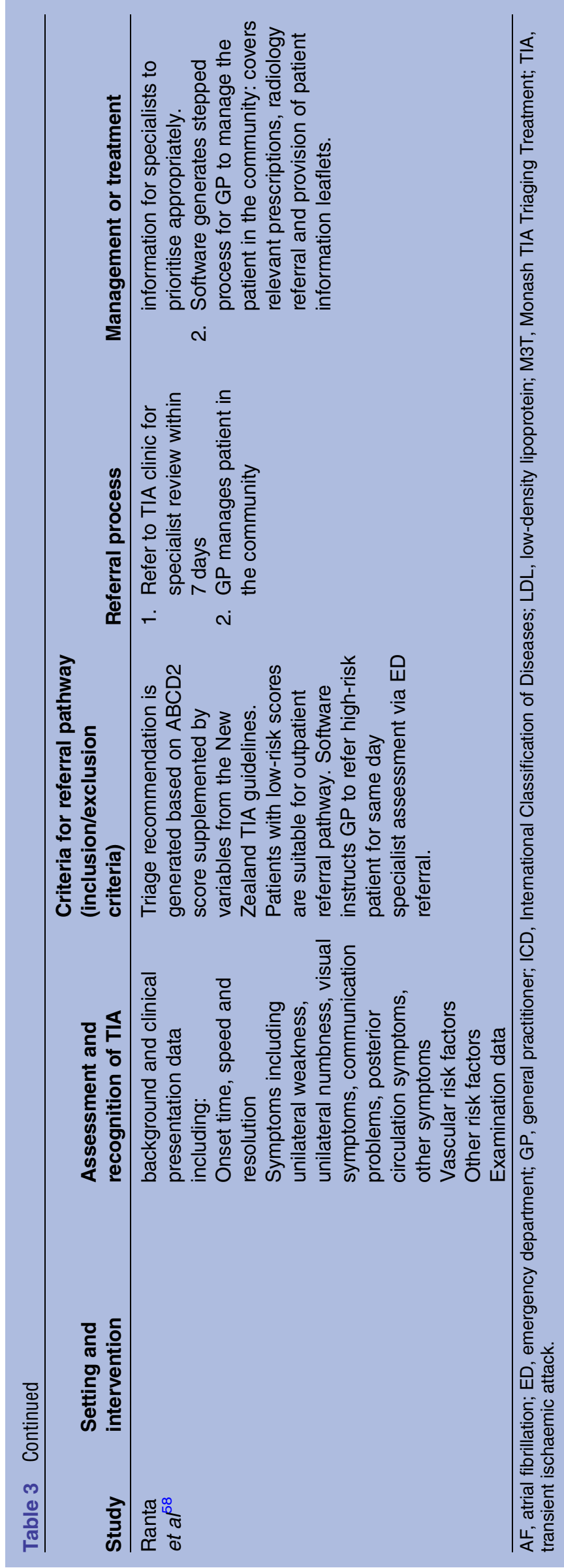

Four studies ${ }^{52} 515657$ described the training and implementation processes provided to family doctors to support TIA referral pathways. These involved information leaflets about TIA and the referral pathways, distributed before and during the studies. Ranta et $a \bar{l}^{5}$ provided GP training on TIA and stroke management. Jeerakathil $e t a l^{56}$ also reported that an education strategy, for doctors and the general public, was undertaken. Training and implementation processes are described in table 4.

\section{Processes and outcomes}

Six studies ${ }^{51-55} 58$ reported stroke rates at 90 days, varying from $1.2 \% \quad(n=13)^{52}$ and $(n=2)^{58}$ to $2.1 \%$ $(\mathrm{n}=6) .^{6}$ Montassier et a $\tilde{p}^{3}$ also reported that three TIAs occurred, representing $5 \%$ of low-risk patients with TIA referred to stroke clinic by emergency physicians. In that study, the confirmed stroke rate was $1.7 \%$ whereas predicted stroke rates at 90 days (predicted using the ABCD2 tool) was $9.7 \%$. Lavallée et a $\overline{5}^{2}$ identified the predicted stroke rate of all presenting patients as $6 \%$ compared with the actual figure of $1.2 \%$. Four studies $^{62-54}$ reported that between $44 \%$ and $82.6 \%$ of suspected low-risk patients with TIA were referred through the pathways designed to avoid hospital admission. Ranta et $a l^{58}$ reported that $76 \%$ of patients managed by GPs using the decision support tool received management consistent with national guidelines compared with $41 \%$ of patients managed by GPs who did not have access to the tool. Outcomes are reported in table 5 .

Kerr et $a l^{51}$ reported that delays in clinic assessment and carotid surgery for patients with TIA reduced significantly $(p<0.01)$ after the introduction of their hotline-from 58 days before (range 6-135) to 21.5 days after (range $5-82)$. Two-thirds $(67 \%$ : $\mathrm{n}=248$ ) of cases referred using their hotline were seen by a specialist within 24 hours; most cases $(94 \%$ : $n=347)$ were seen by a specialist within 96 hours. Of the $88 \%$ of GPs surveyed about the pathway, 94\% were 'very satisfied' with the process; no specialist described any critical incident because the hotline call disrupted their activity. No other studies reported these data.

Sanders $e t a \bar{l}^{4}$ and Rothwell et $a l^{6}$ reported the difference in stroke risk before and after the implementation of their pathway (at 90 days). For patients with confirmed TIA, Sanders $e t a l^{54}$ found a $3.78 \%(95 \%$ CI $-0.19 \%$ to $9.89 \%$ ) reduction in stroke risk following implementation of their pathway-from $5.84 \%$ before (95\% CI $3.1 \%$ to $10.73 \%)$ to $1.74 \%$ after $(95 \%$ CI $0.88 \%$ to $3.39 \%$ ). Rothwell et at provided an adjusted HR for stroke risk following implementation of their pathway of 0.20 (95\% CI 0.8 to $0.49 ; \mathrm{p}=0.0001)$. Stroke risk was reportedly $10.3 \%$ before pathway implementation compared with $2.1 \%$ after $(\mathrm{p}=0.001)$.

Ranta et $a \bar{l}^{58}$ reported economic analysis favouring the use of electronic decision support by GPs to triage patients with suspected TIA and stroke with a treatment 
Table 4 Referral pathway implementation processes

\begin{tabular}{|c|c|c|}
\hline Study & Setting & Implementation process, including training and educational materials \\
\hline Sanders et $a^{54}$ & ED & No details reported \\
\hline Montassier et $a^{53}$ & ED & No details reported \\
\hline Griffiths et $a^{55}$ & ED & No details reported \\
\hline Lavallee et $a^{52}$ & Primary care & $\begin{array}{l}\text { Leaflet on TIA emailed to family doctors, cardiologists, neurologists, ophthalmologists and } \\
\text { EDs with information on definition, key symptoms, risks, main causes and emergency } \\
\text { treatment of TIA emphasising opportunity to prevent potentially devastating stroke. } \\
\text { Leaflet also advised of TIA clinic and free hotline phone number. }\end{array}$ \\
\hline Rothwell et $a^{\rho}$ & Primary care & No details reported \\
\hline Kerr et $a^{\not 1}$ & Primary care & $\begin{array}{l}\text { All GPs in area were sent written guidelines and hotline telephone number by email and } \\
\text { post twice, } 6 \text { months apart } \\
\text { Reminder about service on footnote of every subsequent letter to GPs }\end{array}$ \\
\hline Jeerakathil et $a^{56}$ & Primary care & $\begin{array}{l}\text { Pocket cards and PDF documents distributed province wide } \\
\text { Presentations given } \\
\text { Education modules about TIA management and slide sets created } \\
\text { TIA triaging algorithm adopted as TIA education strategy by province stroke strategy with } \\
\text { materials on website } \\
\text { Knowledge of protocol shared with staff involved in care of patients who suffered stroke; } \\
\text { communication with all stroke prevention clinics } \\
\text { Public education campaign about signs and symptoms of stroke }\end{array}$ \\
\hline $\begin{array}{l}\text { Ranta et } a^{57} \\
\text { Ranta et } a{ }^{58}\end{array}$ & Primary care & $\begin{array}{l}\text { All study GPs were invited to an education session reviewing management of TIA and } \\
\text { stroke, also with a briefing about study processes. Posters were displayed in study } \\
\text { practices advising patients of the trial. }\end{array}$ \\
\hline
\end{tabular}

Table 5 Outcomes

\begin{tabular}{|c|c|c|c|c|}
\hline Study & $\begin{array}{l}\mathrm{n} / \mathrm{N}(\%) \text { of patients with } \\
\text { suspected low-risk TIA } \\
\text { entering referral pathway }\end{array}$ & $\begin{array}{l}\text { 90-day stroke rate } \\
\text { n/N (\%) }\end{array}$ & $\begin{array}{l}\text { Unadjusted } \\
\text { OR }(95 \% \mathrm{Cl}) \mathrm{p}\end{array}$ & $\begin{array}{l}\text { Adjusted } \\
\text { HR }(95 \% \text { CI) p }\end{array}$ \\
\hline Sanders et $a^{F^{4}}$ & $301 / 488(83)$ & $\begin{array}{l}7 / 468 \text { (1.5) intervention } \\
7 / 150 \text { (4.67) control }\end{array}$ & $3.78(-0.19$ to 9.89$)$ & 0.43 I (0.12 to 1.59$) 0.21)$ \\
\hline Montassier et $a^{F^{3}}$ & $62 / 118(52)$ & $\begin{array}{l}1 \text { (1.7) stroke } \\
3 \text { (5) TIA }\end{array}$ & Not reported & Not reported \\
\hline Griffiths et $a^{55}$ & Not reported & $3 / 200(1.5)$ & Not reported & Not reported \\
\hline Lavallee et $a^{\Gamma^{2}}$ & $808 / 1085(74)$ & Not reported & Not reported & Not reported \\
\hline Rothwell et af & $281 / 644(44)$ & $6 / 281(2.1)$ & Not reported & $0.20(0.08$ to 0.49$) ; 0.0001$ \\
\hline Ranta et $a^{p^{8}}$ & $172 / 291(59)$ & $\begin{array}{l}2 / 172(1.2) \\
\text { (intervention) } \\
5 / 119(4.2) \text { (control) }\end{array}$ & $\begin{array}{l}0.27(0.05 \text { to } 1.41) \\
0.098\end{array}$ & $\begin{array}{l}\text { Not possible to calculate } \\
\text { due to small number of } \\
\text { events }\end{array}$ \\
\hline
\end{tabular}

TIA, transient ischaemic attack.

cost ratio of 0.65 (95\% CI 0.47 to $0.91, p=0.013)$. No increased adverse events were recorded. Clinician feedback was positive.

Other results provided by the included studies may be of use in developing our intervention. For example, Griffiths et $a \iota^{55}$ reported that some included patients were found to have a diagnosis other than TIA, including migraine, presyncope, Bell's palsy and seizure with TIA-mimicking symptoms. Sanders et $a l^{54}$ reported that there were no significant differences in stroke outcome between patients who were admitted (n2/N85; 2.35\%) and patients who were not admitted (n5/N4.3; 1.24\%). Lavalée $e t a \varphi^{2}$ found that $74 \% \quad(\mathrm{n}=808)$ of their included patients did not require admission following examination at their 24-hour access clinic.

\section{DISCUSSION}

\section{Summary of findings}

We identified nine international papers reporting eight studies which described pathways to refer patients with suspected TIA for specialist evaluation. In all cases, prehospital decisions about patient care were made by physicians. We identified five pathways which were delivered in primary care, where family doctors identified and referred patients with suspected TIA through an electronic decision support tool, a consultant-led telephone service or directly to clinic. In three studies, ED physicians assessed and referred suitable patients to prevent hospital admission. Outcome data suggested that numbers experiencing another stroke or TIA within 90 days were reduced in patients treated through these 
pathways. Our literature review did not reveal any pathways used by paramedics. There was limited comparative evidence about effects of these pathways on patient outcomes. Only one study used a randomised controlled design and others were limited by not having a controlled comparator group. Two of the included papers were protocols and no results were reported for one of these. Findings should be treated cautiously, although the pathways did not appear to negatively affect patient safety.

\section{Strengths and limitations}

We followed a systematic approach based on guidance for carrying out a scoping review and reported our methods fully in line with guidance. ${ }^{38} 44$

Two researchers had carried out the search and screening stages. We did not undertake a full systematic review since our objective was to inform intervention development in our feasibility study and we were concerned about timescales as experienced by other authors. ${ }^{45}$ We therefore took a pragmatic decision to balance thoroughness and transparency while delivering timely scoping review results in order to inform development of intervention and implementation of our trial. We also discussed methods and findings within the study team to assess and monitor processes.

We did not assess reporting quality of papers and chose to include all study designs in order to search widely across the research literature. ${ }^{38} 41$ However, all papers were published in international peer-reviewed journals and we have reported study results to aid interpretation, in line with recommendations. ${ }^{38}$

\section{Implications for practice and research}

Suspected TIA is common; identification and appropriate referral may be an opportunity to prevent subsequent stroke. ${ }^{2-5}$ Timely access to specialist evaluation is therefore important, particularly since two out of three cases diagnosed in hospital can be missed and onward referrals from hospital to specialist services are often delayed. ${ }^{13} 59$

This review extends the findings of Ranta and Barber $^{60}$ by describing an additional four prehospital pathways for patients with TIA. In this study, we have identified features of referral pathways which safely avoided the need for patients with low risk of further TIA or stroke to be admitted to hospital. Physicians used a decision tool to assess and triage patients—software, algorithms or checklists-although stroke physicians also had direct input to the pathway by contributing to triage decisions, particularly within primary care. Using the decision tool, physicians followed predefined steps to communicate patient details directly to a specialist or central point where specialist review would be arranged. Antiplatelet therapy was prescribed (usually aspirin) unless contraindicated. These pathways were used by family doctors and ED physicians but there is no evidence of use by paramedics.
The decision tools ranged from a simple yes/no checklist of five questions to a computer-based algorithm incorporating real-time and historic data to offer referral options. In New Zealand, Ranta $e t a \bar{l}^{58}$ reported that electronic decision assistance systems reduced unnecessary ED and neurospecialist investigation. Meanwhile a UK-tested hospital online system has stratified and speedily referred patients with TIA for clinical assessment with no patients receiving wrong risk scores. ${ }^{61}$

Our findings contribute evidence to support using a risk assessment procedure to aid clinical assessment in the prehospital environment with the potential to extend pathways for patients experiencing less urgent conditions to avoid hospital admission. ${ }^{18-27}$ Correct diagnosis of TIA and assessment of risk of future events is recognised to be challenging, since symptoms are temporary and mimic other, often common, conditions. ${ }^{12}{ }^{14}$ However, several studies described using the ABCD2 tool to assess risk of further TIA or stroke, without reported difficulties. This suggests the tool can be used to assess and triage patients presenting in the community before onward referral. The Royal College of Physicians identified that paramedics need to be able to identify stroke and TIA cases and called for further research to validate safe and appropriate care pathways (p. 61) $)^{14}$ in the prehospital setting. Decision support tools contribute evidence to enhance risk assessment procedures and support clinical appraisal. Although paramedics are risk averse and want a process to 'cover our backs, ${ }^{62}$ computerised clinical decision support has enabled them to refer twice as many patients to appropriate treatment in place of hospital conveyance, with potential cost-savings. However, paramedics' use of electronic processes is not widespread. ${ }^{20}$ Our findings show that simple checklists, algorithms and computer-based automatic population and calculation features of computerised systems are all feasible and safe in the prehospital setting.

The lack of evidence about paramedic referral pathways highlights the need for further research. The safety and acceptability of referral pathways, to patients and to providers and commissioners of healthcare, is not known nor their effect on resource usage. We identified three questions for immediate investigation, in order to understand the feasibility, safety and effects of prehospital referral of patients with suspected TIA:

- Can paramedics safely identify patients with suspected TIA and assess risk of further TIA or stroke?

- Do prehospital referral pathways enable patients to see specialist clinicians in a timely way?

- How do prehospital referral pathways affect patients' experience, treatment and outcomes?

\section{CONCLUSION}

The scoping method allowed us to identify and describe existing knowledge about referral of patients with TIA to avoid hospital admission. This has shown that there is 
limited evidence describing pathways delivered by family doctors or emergency care physicians and none for paramedics. The identified pathways used checklists to diagnose TIA and identify patients for onward transport or admission to hospital or direct referral to a specialist stroke clinic. Referral arrangements were communicated by fax or telephone hotline and patients received bespoke information and interim medication such as aspirin before being left at home.

The absence of evidence about paramedic referral pathways underlines the need for research into safe and effective processes to optimise treatment of patients with TIA and reduce the burden on hospitals and EDs. Our research team includes paramedics, ambulance services managers, nurses, stroke clinicians and patients alongside experienced trialists. We have used findings from this review alongside results from a survey of UK ambulance services and clinical and operational expertise from stroke, ED and prehospital practitioners, to develop and test a referral pathway protocol for paramedics to use when responding to patients with suspected TIA. We will investigate the feasibility of applying and evaluating this pathway to assess whether it can be delivered by paramedics and is safe and acceptable for patients, in order to plan a fully powered multicentre randomised trial if indicated.

Acknowledgements The authors acknowledge the support and advice of the TIER Trial Management Group.

Contributors BAE undertook searches, screening, drafted the results and led writing of this paper. MJ undertook searches and screening. BAE and JB extracted data. KA, GAF and TQ provided expertise about management of transient ischaemic attacks. CM and NR provided expertise about management and practice of prehospital services; JB, AP, ACS and HS provided health services research and methodological expertise. ADP and SW provided patient and carer experience and perspectives. All authors contributed to the review. All authors contributed to the paper, read and agreed the final manuscript.

Funding This work was supported by Health and Care Research Wales through their Research for Patient and Public Benefit (RfPPB) stream (award number 1053)

Competing interests None declared.

Provenance and peer review Not commissioned; externally peer reviewed.

Data sharing statement No additional data are available.

Open Access This is an Open Access article distributed in accordance with the Creative Commons Attribution Non Commercial (CC BY-NC 4.0) license, which permits others to distribute, remix, adapt, build upon this work noncommercially, and license their derivative works on different terms, provided the original work is properly cited and the use is non-commercial. See: http:// creativecommons.org/licenses/by-nc/4.0/

\section{REFERENCES}

1. Albers GW, Caplan LR, Easton JD, et al. Transient ischemic attack -proposal for a new definition. N Engl J Med 2002;347:1713-16.

2. Kleindorfer D, Panagos $P$, Pancioli $A$, et al. Incidence and short-term prognosis of transient ischemic attack in a population-based study. Stroke 2005;36:720-3.

3. Coull AJ, Lovett JK, Rothwell PM. Population based study of early risk of stroke after transient ischaemic attack or minor stroke: implications for public education and organisation of services. BMJ 2004;328:326.
4. Johnston SC, Gress DR, Browner WS, et al. Short-term prognosis after emergency department diagnosis of TIA. JAMA 2000;284:2901-6.

5. Olson DM, Cox M, Pan W, et al. Death and rehospitalization after transient ischemic attack or acute ischemic stroke: one-year outcomes from the adherence evaluation of acute ischemic stroke-longitudinal registry. J Stroke Cerebrovasc Dis 2013;22: e181-8.

6. Rothwell PM, Giles MF, Chandratheva A, et al. Effect of urgent treatment of transient ischaemic attack and minor stroke on early recurrent stroke (EXPRESS study): a prospective population-based sequential comparison. Lancet 2007;370:1432-42.

7. Department of Health. Reducing Brain Damage: Faster access to better stroke care. 2005. http://www.nao.org.uk/wpcontent/uploads/ 2005/11/0506452.pdf (accessed 20 Feb 2015).

8. Castledine G, Close A. Stroke and transient ischaemic attack: an overview. In: Castledine G, Close A, eds. Oxford Handbook of Adult Nursing. Oxford: Oxford University Press, 2009:46-7.

9. Sprigg N, Machili C, Otter ME, et al. A systematic review of delays in seeking medical attention after transient ischaemic attack. J Neurol Neurosurg Psychiatry 2009;80:871-5.

10. Wilson AD, Coleby $\mathrm{D}$, Regen $\mathrm{E}$, et al. Service factors causing delay in specialist assessment for transient ischaemic attack and minor stroke: a qualitative study of GP and patient perspectives. BMJ Open 2016;6:e011654.

11. Johnston SC, Rothwell PM, Huynh-Huynh MN, et al. Validation and refinement of scores to predict very early stroke risk after transient ischemic attack. Lancet 2007;369:283-92.

12. National Institute for Clinical Excellence. NICE clinical guideline 68 Stroke: diagnosis and initial management of acute stroke and transient ischaemic attack (TIA). 2008. http://www.nice.org.uk/ nicemedia/pdf/CG68NICEGuideline.pdf (accessed 20 Feb 2015).

13. Sales M, Quain D, Lasserson D, et al. Quality of referrals and guideline compliance for time to consultation at an acute neurovascular clinic. J Stroke Cerebrovasc Dis 2015;24:874-80.

14. Intercollegiate Stroke Working Party. National clinical guideline for stroke. London. 2012. http://www.rcplondon.ac.uk/sites/default/files/ nationalclinical-guidelines-for-stroke-fourth-edition.pdf (accessed 20 Feb 2015).

15. Omar A, Penglass RG, Chen MS, et al. A retrospective analysis of inpatient compared to outpatient care for the management of patients with transient ischaemic attack. J Clin Neurosci 2013;20:988-92.

16. Wasserman J, Perry J, Dowlatshahi D, et al. Stratified urgent care for transient ischemic attack results in low stroke rates. Stroke 2010;41:2601-5.

17. Ben-Yakov M, Kapral MK, Fang J, et al. The Association between emergency department crowding and the disposition of patients with transient ischemic attack or minor stroke. Acad Emerg Med 2015;22:1145-54

18. NHS England. Transforming urgent and emergency care services in England: improving referral pathways between urgent and emergency services in England. London: NHS England, 2015.

19. Snooks H, Anthony R, Chatters R, et al. Support and assessment for fall emergency referrals (SAFER 2) research protocol: cluster randomised trial of the clinical and cost effectiveness of new protocols for emergency ambulance paramedics to assess and refer to appropriate community-based care. BMJ Open 2012;2:pii: e002169.

20. Snooks HA, Carter B, Dale J, et al. Support and assessment for fall emergency referrals (safer 1 ): cluster randomised trial of computerised clinical decision support for paramedics. PLOS ONE 2014;9:e106436.

21. Halter M, Vernon S, Snooks $\mathrm{H}$, et al. Complexity of the decision-making process of ambulance staff for assessment and referral of older people who have fallen: a qualitative study. Emerg Med J 2011;28:44-50.

22. Dixon S, Mason S, Knowles E, et al. Is it cost effective to introduce paramedic practitioners for older people to the ambulance service? Results of a cluster randomised controlled trial. Emerg Med $J$ 2009;26:446-51.

23. O'Hara R, Johnson M, Siriwardena AN, et al. A qualitative study of systemic influences on paramedic decision making: care transitions and patient safety. J Health Serv Res Policy 2015;20(Suppl 1):45-53.

24. Snooks $\mathrm{H}$, Williams $\mathrm{S}$, Crouch $\mathrm{R}$, et al. NHS emergency response to 999 calls: alternatives for cases that are neither life threatening nor serious. BMJ 2002;325:330.

25. Snooks H, Kearsley N, Dale J, et al. Towards primary care for non-serious 999 callers: results of a controlled study of "Treat and Refer" protocols for ambulance crews. Qual Saf Health Care 2004;13:435-43. 
26. Snooks $\mathrm{H}$, Foster $\mathrm{T}$, Nicholl J. Results of an evaluation of the effectiveness of triage and direct transportation to minor injuries units by ambulance crews. Emerg Med $J$ 2004;21:105-11.

27. Snooks $\mathrm{H}$, Cheung WY, Close J, et al. Support and Assessment for Fall Emergency Referrals (SAFER 1) trial protocol. Computerised on-scene decision support for emergency ambulance staff to assess and plan care for older people who have fallen: evaluation of costs and benefits using a pragmatic cluster randomised trial. BMC Emerg Med 2010;10:2.

28. National Health Executive. Demand pressures affecting ambulance response times. 2014. http://www.nationalhealthexecutive.com/ Health-Care-News/demand-pressures-affecting-ambulanceresponse-times- (accessed 25 Feb 2015)

29. BBC News. Firefighters step in to aid Oxfordshire ambulance demand. 2015 (Accessed 26 Feb 2015). http://www.bbc.co.uk/news/ uk-england-oxfordshire-30724426

30. BBC News. Police say ambulance service putting demand on its resources. 2014 (accessed 26 Feb 2015). http://www.bbc.co.uk/ news/uk-england-essex-25669203

31. Intercollegiate Stroke Working Party. National clinical guideline for stroke. 4th edn. London: Royal College of Physicians, 2016.

32. Rothwell PM, Giles MF, Flossmann E, et al. A simple score (ABCD) to identify individuals at high early risk of stroke after transient ischaemic attack. Lancet 2005;366:29-36.

33. Wardlaw J, Brazzelli M, Miranda $\mathrm{H}$, et al. An assessment of the cost-effectiveness of magnetic resonance, including diffusionweighted imaging, in patients with transient ischaemic attack and minor stroke: a systematic review, meta-analysis and economic evaluation. Health Technol Assess 2015;18:369-70.

34. Rae V, Ford G, Price C. Prehospital assessment of stroke: time is brain. J Paramed Pract 2011;3:483-8.

35. Mant J, Ryan R, McManus R, et al. What is the optimum model of service delivery for transient ischaemic attack? Report for the National Co-ordinating Centre for NHS Service Delivery and Organisation R\&D (NCCSDO), April 2008.

36. Shanyinde M, Pickering RM, Weatherall M. Questions asked and answered in pilot and feasibility randomized controlled trials. BMC Med Res Methodol 2011;11:117.

37. Smith L, McCourt O, Henrich M, et al. Multiple myeloma and physical activity: a scoping review. BMJ Open 2015;5:e009576.

38. Arksey H, O'Malley L. Scoping studies: towards a methodological framework. Int J Soc Res Methodol 2005;8:19-32.

39. Anderson S, Allen P, Peckham S, et al. Asking the right questions: scoping studies in the commissioning of research on the organisation and delivery of health services. Health Res Policy Syst 2008;6:7.

40. Grant MJ, Booth A. A typology of reviews: an analysis of 14 review types and associated methodologies. Health Info Libr J 2009;26:91-108.

41. Hamm MP, Chisholm A, Shulhan J, et al. Social media use among patients and caregivers: a scoping review. BMJ Open 2013;3: e002819.

42. Zinszer K, Verma AD, Charland K, et al. A scoping review of malaria forecasting: past work and future directions. BMJ Open 2012;2: e001992.

43. Armstrong R, Hall BJ, Waters E. 'Scoping the scope' of a Cochrane review. J Public Health 2011;33:147-50.
44. Levac D, Colquhoun H, O'Brien KK. Scoping studies: advancing the methodology. Implement Sci 2010;5:69.

45. Brien S, Lorenzetti D, Lewis S, et al. Overview of a formal scoping review on health system report cards. Implement Sci 2010;5:2-10.

46. Centre for Reviews and Dissemination. Systematic reviews: CRD's guidance for undertaking reviews in healthcare. York: CRD, 2001.

47. Daudt HML, van Mossel C, Scott SJ. Enhancing the scoping study methodology: a large, inter-professional team's experience with Arksey and O'Malley's framework. BMC Med Res Methodol 2013;13:48

48. Higgins JPT, Green S. Cochrane Handbook for Systematic Reviews of Interventions Version 5.1.0 2011: The Cochrane Collaboration.

49. Moher D, Alessandro L, Jennifer T, et al. Preferred Reporting Items for Systematic Reviews and Meta-Analyses: the PRISMA Statement. PLoS Med 2009;6:e1000097.

50. Ritchie J, Spencer L. Qualitative data analysis for applied policy research. In: Bryman A, Burgess RG. eds. Analysing qualitative data. London: Routledge, 1994:173-94.

51. Kerr E, Arulraj N, Scott M, et al. A telephone hotline for transient ischaemic attack and stroke: prospective audit of a model to improve rapid access to specialist stroke care. BMJ 2010;341:c3265.

52. Lavallée $\mathrm{PC}$, Meseguer $\mathrm{E}, \mathrm{Abboud} \mathrm{H}$, et al. A transient ischaemic attack clinic with round-the-clock access (SOS-TIA): feasibility and effects. Lancet Neurol 2007;6:953-60.

53. Montassier E, Lim T-X, Goffinet N, et al. Results of an outpatient transient ischemic attack evaluation: a 90 day follow-up study. $J$ Emerg Med 2013;44:970-5.

54. Sanders LM, Srikanth VK, Jolley DJ, et al. Monash transient ischemic attack triaging treatment safety of a transient ischemic attack mechanism-based outpatient model of care. Stroke 2012;43:2936-41

55. Griffiths D, Sturm J, Heard R, et al. Can lower risk patients presenting with transient ischaemic attack be safely managed as outpatients? J Clin Neurosci 2014;21:47-50

56. Jeerakathil T, Shuaib A, Majumdar SR, et al. for the ASPIRE Investigators. The Alberta Stroke Prevention in TIAs and mild strokes (ASPIRE) intervention: rationale and design for evaluating the implementation of a province-wide TIA Triaging system. Int $J$ Stroke 2012;9:135-43.

57. Ranta A, Dovey S, Weatherall D, et al. Efficacy and safety of a TIA/ stroke electronic support tool (FASTEST) trial: study protocol. Implement Sci 2012;7:107.

58. Ranta A, Dovey S, Weatherall $\mathrm{M}$, et al. Cluster randomised controlled trial of TIA electronic decision support in primary care. Neurology 2015;84:1545-51.

59. Tu K, Wang M, Young J, et al. Validity of administrative data for identifying patients who have had a stroke or transient ischemic attack using EMRALD as a reference standard. Can J Cardiol 2013:29:1288-394.

60. Ranta A, Barber PA. Transient ischemic attack service provision. Neurology 2016;86:947-53.

61. Guvler PC, Lognathan T, Ude S, et al. An innovative online system to risk-stratify and directly refer TIA patients: HOT-TIA. Int J Stroke 2013;8(Suppl 3):38.

62. Porter A, Snooks H, Youren A, et al. "Covering our backs": ambulance crews' attitudes towards clinical documentation when emergency (999) patients are not conveyed to hospital. Emerg Med $J$ 2008;25:292-29. 